\title{
Research Note: Machinery, Manumission, and Economic Machinations
}

David J. Edwards, (corresponding author) Faculty of Computing, Engineering and Built Environment, Birmingham City University, Birmingham, B5 5JU, UK.

$$
\text { drdavidedwards@aol.com }
$$

Erika Pärn, Faculty of Computing, Engineering and Built Environment, Birmingham City University, Birmingham, B5 5JU, UK. Erika.Pärn@bcu.ac.uk

Peter E.D. Love, School of Civil and Mechanical Engineering Curtin University, GPO Box U1987, Perth. WA 6845, Australia. plove@iinet.net.au

Hatem El-Gohary, Birmingham City Business School, Birmingham City University, Birmingham, B5 5JU, UK. Hatem.Elgohary@ bcu.ac.uk

Submission: February 2016

Revision: May 2016

Acceptance: June 2016

The authors are grateful for the comments by anonymous reviewers, and Mr Barry Robinson (Finning, Caterpillar, UK), on prior drafts of this article. Send correspondence to: David J. Edwards, (corresponding author) Faculty of Computing, Engineering and Built Environment, Birmingham City University, Birmingham, B5 5JU, UK Email: drdavidedwards@aol.com; Tel: 0044(0) 1902820200 


\title{
Research Note: Machinery, Manumission, and Economic Machinations
}

\begin{abstract}
This research note reports upon advancements in computerization and big data creation within the off-highway plant and machinery sector. A thematic literature review synthesizes a disparate range of research initiatives and industrial developments and highlights specific examples of technological developments. A discussion regarding impact upon future employment concludes that rather than creating mass unemployment, computerization will change the employment horizon and continue to shape the global economic community. Education is quintessentially important to humanity which must master the machine and not become a slave to technology. Future proofing of educational provisions will therefore feature heavily in tomorrow's employment market. This provocative research note advances new ideas and theoretical perspectives that are specifically designed to stimulate academic debate in this novel and rapidly developing area of scientific endeavor.
\end{abstract}

\section{KEYWORDS}

Big data, computerization, robotics, off-highway plant and machinery.

\section{Introduction}

“Homo Sapiens have outgrown their use...” Bowie (1971)

The rapid pace of computerization has created a digital economy to challenge the modern capitalist economy; societal, political and economic ramifications of this change are profound, not least upon employment, education and prosperity (Parayil, 2005). The digital 
economy manifests from two key sources: i) the transformation effects of general purpose technologies (hardware) in the field of information and communication; and ii) the overwhelmingly vast inter-connectivity afforded by the internet. Unlike the Industrial Revolution, the digital age is maturing at an exponential pace. In 2010, the internet contained an estimated five hundred billion gigabytes of digital content but increasingly, experts refer to digital content in yottabytes (i.e. a trillion terabytes) (Bollier, 2010). This growth trend is fueled by the rise in internet traffic which is doubling every two to three years, with mobile internet traffic doubling every year (EU, 2014). Ross (2016) reports that the currently estimated 16 billion internet connected devices will increase to 40 billion by 2020 . The voluminous data generated (and knowledge contained within such) signifies that whilst iron represented the Industrial Revolution's raw material, data constitutes the raw material of the information age. As well as fueling prosperity, the information age has also created opportunities for cybercrime and terrorists. The number, cost and sophistication of these attacks is increasing at an alarming rate and the value of crime is estimated to cost the global economy billions of pounds (UK Sterling) each year (Ablon, Libicki, and Golay, 2014).

The digital revolution far exceeds the confines of the information and communication technology sector, and ubiquitous mobile computing provides a menagerie of mobile digital devices that generate vast quantities of data, information and knowledge for businesses and government - so called big data. Big data has the inherent potential to uncover patterns, trends and associations related to machinery, human behavior and the interactions between the two. Industries that increasingly use mobile machinery are no exception. Frey and Osbourne (2014) report that this observed growth is founded upon advances in machine learning (ML) and mobile robotics (MR). The term robot has its etymological roots in the word serf and the unlimited productive capacity afforded by computers and robotic self- 
regulated machines will shape economies and alter employment markets (Levy and Murnane, 2012).

Automation of mobile machinery within the off-highway plant and equipment sector has similarly proliferated. Off-highway plant and machinery (which is often erroneously referred to as construction plant and equipment) consists of largely mobile self-propelled machines that are operated in a range of heavy industries including construction, civil engineering, quarrying, warehouse and distribution and mining. Typical machines include road rollers, articulated or rigid dump trucks, cranes and excavators. This research note reviews developments in the field of automated off-highway plant and equipment and discusses the social and economic ramifications of such technological advancements, where the discussion is based upon a synthesis of literature and the authors' twenty years of experience working within this field of science. The purpose is to generate new ideas and provide polemic clarity geared to intellectually challenge readers from across a range of academic and industrial disciplines.

\section{Manumission and Technological Transformation}

Early off-highway plant and machinery shared a symbiotic linkage with the operator, and represented a mechanical extension of human physicality, where human senses were transferred through machinery to complete physical work effort without exerting load upon the operator's musculoskeletal frame. This pseudo-cybernetic organism (i.e. man and machine inextricably linked) led to manumission but remained dependent upon operator cognitive ability (i.e. skill, knowledge and competence) to guide the machinery to complete predefined tasks. The advent of globalization intensified competition within world economies by eroding regional monopolies, increasing competition and consequently stimulating a drive 
to increase productivity performance. Reacting to customers' demands, original equipment manufacturers (OEMs) acknowledged that human intervention impacted upon machinery productivity performance in various ways and sought to better understand these through work study. For example, consider a tracked face-shovel excavator used at the blast face in quarries where the machine's performance is dependent upon factors such as: a bucket fill factor, slew times and break-out forces. Modelling of work study data revealed the extent to which operator performance, and other environmental conditions (such as soil type and meteorological conditions), impacted upon machine performance. A renewed focus upon operator training and competence development followed but new knowledge acquired on human behavior (primarily limitations to machine utilization, i.e. hours operated) revealed that maximizing machinery productivity efficiency was a persistent issue. The natural extension was to design-out human error, omissions or inactivity via the development of automation and robotics.

Robotics now effectively challenge the manual operation and maintenance of off-highway plant and machinery. Recent developments in belief space (i.e. the ability of a robot to make intelligent decisions based upon complex algorithmic computations) have enabled tasks that were previously too complex for robots to undertake, to be achieved with considerable aplomb (e.g. deceptively simple tasks that require an assessment of weight, fragility and density or the gravitational forces exerted upon an object). Belief space has transformed robots from a two-dimensional to a three-dimensional life via cloud robotics. The robot (Robot B-9) in the 1960's television series Lost in Space would be hugely expensive and require a multi-million pound investment in standalone hardware and software technology to operate. Mobile communications via cloud technology have removed this financial barrier (and increased computational power) by allowing internet connected devices to communicate 
algorithmically via the cloud, providing the machines with information and instruction. Robots have become a servant class that can replace not only hard labor but also work that requires more cognitive skills and ability. Aviation was one of the first industries to embrace the incredible sophistication and versatility offered by mobile computerization, in the areas of civilian aircraft and remote controlled drones (Holland, Webster, Curry, Tyrell, Gauntlett, Brett, Becker, Hoag, and Vaglienti, 2001). Indeed, most aircraft today have very limited human interaction. Whilst computerization is being increasingly adopted within the realm of off-highway plant and machinery, several limitations are apparent, the most prominent being related to the value of the machinery purchased and not necessarily the technological costs. Smaller machines under circa 10 tons in weight (e.g. the micro or mini excavator) are often treated as disposable white goods and liberally used and abused until written-off over a predefined depreciation term (often three-five years) (Edwards, Harris and McCaffer, 2003). For this reason, the majority of automation and robotic research in the off-highway plant and machinery sector has predominantly focused upon larger and more expensive machines $(>30$ tons and $\leq 200$ tons in weight).

\section{Technological Developments in the Off-Highway Plant and Machinery Sector}

A peculiarity of the off-highway plant and machinery sector is that advancements in computerization, automation and robotics sometimes co-exist in a parallel universe.

Academic institutions typically pursue knowledge via research grants won, $\mathrm{PhD}$ completions and research papers published. OEMs, whose research and development departments employ vast resources, ruthlessly pursue profitability and market share. When the two converge onto a common research project, the outcomes are remarkable but too often academic outputs stagnate in a self-referential cycle where the self-serving principal objective is publish or peril (Neill, 2008). Despite this concern, extraordinary advancements in the sector have been 
made. A brief review follows to provide a contextual backdrop by which to measure current progress; of particular note, many of these innovations are based upon advanced sensor technology.

On-board condition based maintenance monitoring. Maintenance is a necessity for sustaining machinery availability and reliability, which in turn ensures productivity, product quality, timely product delivery and a safe working environment (Tran and Yanga, 2012). Simultaneously, maintenance preserves a machine's working life and extends its residual value (Edwards et al., 2003; Edwards and Holt, 2009). On-board condition monitoring techniques have capitalized upon sensor technology to provide direct, on-line, big data streaming to record the health (or otherwise) of critical components, including most rotating and reciprocating parts (Heng, Zhang, Tan and Mathew, 2009). Noise and temperature signatures of healthy components or compartments are then compared to these actual values to determine the presence and extent of wear (Turner and Huff, 2003; Choy, Mugler, and Zhou, 2003). A component is a single mechanical item, such as a piston ring within an engine; the engine itself represents the compartment, which contains numerous components. The major beneficial ramification of on-board condition monitoring is that parts and components are no longer replaced on a time-usage basis, a particularly wasteful strategy as parts that could have extended useful life are simply replaced regardless (Komatsu, 2016). Rather, intelligent management decisions, founded upon algorithmic calculations, are used to determine the most economical time to conduct maintenance in order to prevent breakdown and machinery downtime. 
Health and safety. Research into preserving health and safety focuses upon protection of persons who may be affected by machinery usage. Some sectors, for example the construction industry, have an unfortunate record of injuries and fatalities (Edwards and Nicholas, 2002) and two common root causes are inadequate operator competence (Edwards, 2003) and/ or deficient on-site maintenance (Edwards and Love, 2016). To counter the causation of these incidents, a number of research studies have been completed on a broad range of topics - notably, each study has attempted to augment machine performance by bypassing limitations in an operator's cognitive ability. For example, Pizarro et. al., (1997) experiments with auditory collision warning signals for a crane/overhead power line collision simulated scenario whilst Riaz, Edwards and Thorpe, (2006) and Chae and Yoshida (2010) utilize radio frequency identification tags to prevent machine and/ or pedestrian collision. Chen, Chao and Kim (2002) focus upon recent hardware and software developments in machine vision systems for multispectral and hyperspectral inspection of food, whilst Trivedi, Gandhi and McCall (2003) use computer vision technology to develop safer vehicles. Future developments look set to combine all artificial sensory perceptions in one integral system and could remove human error or omissions and mitigate health and safety incidents.

Telematics. Telematics are a standard feature on most off-highway plant and machinery, with many being factory installed by OEMs. Within academia, research conducted has been myriad. For example, Ko (2010) develops location sensing algorithms to monitor the movement of people, materials and plant, while Teizer, Allead, Fullerton and Hinze (2010) develop real time proximity detection to alert employees and vehicle operators of potential struck-by incidents. Roberts, Dodson and Ashkenazi (1999) demonstrate that global positioning systems (GPS) provide dynamic guidance for autonomous machinery and 
positioning accuracy to within millimeters. At first telematics was used primarily to drive optimization of mechanical efficiency, safety and production performance but the increasingly rich and varied big data collated has enabled telematics to instigate behavioral change in operators. For example JCB's LiveLink (JCB, 2016) can monitor machine idle time and therefore utilization rates, whilst Volvo's Eco Operator System (Volvo, 2016) measures the operator's driving technique with a view to improving behavior. Other advances in telematics relate to machine performance and security. For example, Carmichael and Edwards (2005) report upon stolen plant and machinery recovery using mobile communications. Each year, the value of stolen plant and machinery is estimated to cost in excess of $£ 100$ million (UK sterling) (Gardner, Morrow and Wyers, 2002). The threat of organized crime has encouraged OEMs to develop bespoke anti-theft computerized telecommunication devices, such as Hitachi's Tracking and E-Guard system that contains an integrated immobilizer system (Hitachi, 2016). Industry experts suggest that in excess of 4050 key machinery parameters are now monitored and managed via telematics - a trend that is set to increase considerably in response to customer expectations and demand.

Operations optimization. Optimization encapsulates many of the aforementioned areas of computerization (e.g. health and safety, condition monitoring and telematics), hence demonstrating the significant overlap between the technologies and their applications. For example, Volvo's EcoOperator system (Volvo, 2016) utilizes sensors to alert management to operator errors, such as leaving the handbrake on whilst travelling, thus avoiding the consequential tangible (direct costs of maintenance or lost production) and intangible financial losses (loss of customer good will and future contracts should project delays occur). Other key developments include: robotic excavator motion control (Wang, Zheng, Yu, Zhou and Shao, 2016); improved decision support for tower crane selection (Marzouk, and 
Abubakr, 2016); and fuel efficiency and population reduction studies in mid-range excavators (Gasoli, Gambarotta, Pompini and Ricoo, 2016)..Commercial entrepreneurs, for example companies such as Vulcan On-Board Scales (Vulcan, 2016), now produce automated measurement devices that are retrofitted to dump trucks to ensure that the load is maximized to achieve fuel economy (and by implication - lower fuel emissions) over an earth-moving contract (Vulcan On-Board Scales, 2016). Lower costs of technology production, combined with insatiable demand from industry for higher profits given pressure from low margins, have undoubtedly fueled advancements in operations optimization. Future growth in this area is anticipated and convergence of computerization, sensor technology and algorithmic solutions into one integral system is inevitable.

\section{Economic Machinations}

Frey and Osbourne (2014) report that in the United States, $47 \%$ of jobs are susceptible to computerization. In one respect, this warning is prophetic. However, the employment horizon will adapt and evolve to the changes in market forces driven by technological progression. Based on the premise of Darwinian theory (Darwin, 1869), neither the strongest nor the most intelligent of the species survive, but rather those who are more adaptable to change. The future for engineering graduates and apprentices is unpredictable because they will enter a rapidly evolving employment horizon where the jobs originally sought will have been replaced by computerization. Two diametrically opposed theoretical positions have arisen from the acknowledgement that robots could replace humanity altogether: i) the utopian perspective (the creative effect); and ii) the dystopian perspective (destructive effect). The utopian perspective suggests that the dreary, dull and repetitive tasks undertaken by robots will free humanity to invest time and energy in more intellectually challenging and rewarding activities. Such would represent a hedonistic lifestyle rooted in abundance, because humanity 
has no work to perform. The dystopian perspective suggests that humanity will no longer be able to support itself economically because robots will complete cognitive and manual work activities faster, more efficiently and at lower cost. As a consequence, humanity splits into two dichotomous groupings namely: i) a small number of super wealthy technological oligarchs who control and exploit computerization for their own benefit; and ii) a huge mass of lower classes with limited or no technological know-how. A nihilistic vision would be one of famine, riots and war based upon scarce resources, social injustice and inequality of wealth.

The only certain thing about the future is uncertainty; the distant future (next 100 years) simply cannot be predicted. However, political machinations on the global economy's future shape will consider these aforementioned theoretical positions and most likely as a result, influence its direction. In the short to medium term (10-20 years), the off-highway plant and machinery sector will continue to evolve and integrate technological solutions but Homo sapiens are unlikely to have outgrown their use. This is because many of the tasks completed by off-highway plant and machinery are bespoke and subject to frequent change during a project's development. Unless steady state conditions can be established on site (and they could be in some instances - e.g. quarries or factories), the likelihood that robots will replace operators is at present minimal. More likely, and based upon recent developments, the sector will continue to adopt computerization as a tool to help overcome the limitations of operators and managers of machinery. Big data will be used to measure machine health, vehicle emissions, safety, production and cost performance but when combined with mobile communications, adjustments must be made to counter operator errors or alert management to pending issues such as incipient breakdown. 


\section{Conclusions}

Computerization, machine learning, robotics and big data are already inseparably linked within the off-highway plant and equipment sector. The technological advancements made in these fields offer exciting innovations that have discernibly improved machine performance and future adaptation looks almost certain. The role of operators will inevitably continue to change and evolve, but technology will most likely improve upon their performance rather than replace them. The unique relationship between operators and their machines could change in one of several ways, namely: i) the pseudo-cybernetic relationship could be used the augment operator performance whilst inside the machine's cab; ii) operators could begin to operate machines externally from the cab via on-site remote control using devices similar to game controllers; and/ or iii) the advent of the keyboard operator may transpire - operators located in offices who operate machines using visualization cameras to guide work activities. Big data generated from on-board sensors linked via mobile communications will prove invaluable to management in automated diagnosis of machinery health, improving the efficiency of managerial decision making and remotely measuring machinery performance.

Big data will play a major role in shaping future operations and management of machinery, and therefore also influence training policies. Labor of the future is being educated today and many classic engineering jobs will alter significantly, simply disappear or be replaced by robots. Government and education providers must future-proof education provisions and foster a culture of lifelong learners who are resilient to change. Other challenges will also be presented, foremost amongst these is cyber-crime emanating from criminals or political activists (so-called hacktivism). In conclusion, whilst computerization and big data promise significant and substantial benefits, they also raise equally significant and substantial dangers, 
such as social inequality and crime, which cannot be ignored. Mankind must hence assert dominion over technology and not become its slave. 


\section{REFERENCES}

Ablon, L. Libicki, M.C. and Golay, A. A.(2014) Markets for Cybercrime Tools and Stolen Data: Hackers' Bazaar, Rand: London.

Bollier, D. (2010) The Promise and Peril of Big Data, The Aspen Institute: Washington, DC. Bowie, D. (1971) Oh! You Pretty Things, Hunky Dory, Parlophone: London.

Carmichael, R. and Edwards, D.J. (2005) Plant Theft and Recovery, a Practitioners' Guide, Off-highway Plant and Equipment Research Centre (OPERC): Dudley, UK.

Chae, S. and Yoshida, T. (2010) Application of RFID Technology to Prevention of Collision Accident with Heavy Equipment, Automation in Construction, Vol. 19, No. 3, pp. 368374.

Chen, Y-R., Chao, K. and Kim, M.S. (2002) Machine Vision Technology for Agricultural Applications, Computers and Electronics in Agriculture, Vol. 36, No. 2-3, pp. 173-191.

Choy, F.K., Mugler, D.H. and Zhou, J. (2003) Damage Identification of a Gear Transmission Using Vibration Signatures, Journal of Mechanical Design, Vol. 125, No. 2, pp. 394-403 Darwin, C. (1869) Of the Species of Origin by Means of Natural Selection, $1^{\text {st }}$ Ed. John Murray: London.

Edwards, D.J. (2003) Accident Trends Involving Construction Plant: An Exploratory Analysis, Journal of Construction Research, Vol. 4, No. 2, pp 161-173.

Edwards, D.J. and Nicholas, J. (2002) The State of Health and Safety in the UK Construction Industry with a Focus on Plant Operator, Journal of Structural Survey, Vol. 20, No. 2, pp 78-87.

Edwards, D.J., Harris, F.C. and McCaffer, R. (2003) Management of Off-highway Plant and Equipment, E and FN Spon: London. 
Edwards, D. J. and Holt, G. D. (2009) Construction Plant and Equipment Management Research: Thematic Review, The Journal of Engineering, Design, and Technology. Vol.7, No. 2, pp. 186-206

Edwards, D.J. and Love, P.E.D. (2016) A Systemic Risk Maintenance Model for Machinery, Accident, Analysis and Prevention. Early Cite - DOI: 10.1016/j.aap.2015.10.031

EU (2014) Working Paper, Digital Economy - Facts and Figures, Expert Group on Taxation of the Digital Economy, Report No.: Digit/008/2014, Brussels. Accessed via: http://ec.europa.eu/taxation_customs/resources/documents/taxation/gen_info/good_gover nance_matters/digital/2014-03-13_fact_figures.pdf (January 2016)

Frey, C.B. and Osborne, M.A. (2013) The Future Employment: How Susceptible are Jobs to Computerisation? Machines and Employment Workshop, Oxford University Engineering Sciences Department and Oxford Martin Programme on the Impacts of Future Technology, September $17^{\text {th }}, 2013$. Accessed via:

http://www.oxfordmartin.ox.ac.uk/downloads/academic/The_Future_of_Employment.pdf (January, 2016).

Gardner, M., Morrow, A. and Wyers, C. (2002) Security Guidance Document for Agricultural and Construction Plant, Police Scientific Development Branch, Hoe Office Policing and Crime Reduction Group, Publication 1/02.

Gasoli, P., Gambarotta, A., Pompini, N. and Ricoo, L. (2016) Hybridization Methodology Based on DP Algorithm for Hydraulic Mobile Machinery - Application to a Middle Size Excavator, Automation in Construction, Vol. 61, pp. 42-57.

Heng, A., Zhang, S., Tan, A.C.C. and Mathew, J. (2009) Rotating Machinery Prognostics: State of the Art, Challenges and Opportunities, Mechanical Systems and Signal Processing, Vol., 23, No. 3, pp. 724-739. 
Hitachi (2016) E-Guard, Hitachi Construction Machinery, Hitachi: Tokyo. Accessed via: http://www.hcme.com/Service-Parts/Service/Global-e-Service/e-Guard (January, 2016)

Holland, G.J., Webster, P.J., Curry, J.A., Tyrell, G., Gauntlett, Brett, D., Becker, J., Hoag, R. and Vaglienti, W. (2001) The Aerosonde Robotic Aircraft: A New Paradigm for Environmental Observations. American Meteorological Society, Vol. 82, No. 5, pp. 889901.

JCB Service (2016) LiveLink, JCB Service: Uttoxeter, UK. Accessed via: http://www.jcb.com/customersupport/livelink.pdf (January, 2016)

Ko, C. (2010) RFID 3D Location Sensing Algorithms, Automation in Construction, Vol. 19, No.5, pp 588-595.

Komatsu (2016) Komtrax, Komatsu: Tokyo. Accessed via: http://www.komatsuamerica.com/komtrax (January 2016)

Levy, F and Murnane, R.J. (2012) The New Division of Labour: How Computers are Creating the Next Job Market, Princetown University Press: Princetown, NJ.

Maghzi, S. (2014) Improved Tower Cranes Operation Using Integrated 3D BIM Model and GPS Technology, Degree of Master of Applied Science (Civil Engineering), Concordia University Montreal, Quebec, Canada. Accessed via: http://spectrum.library.concordia.ca/979151/1/salar_maghzi.pdf (January 2016) Marzouk, M. and Abubakr, A. (2016) Decision Support for Tower Crane Selection with Building Information Models and Genetic Algorithms, Automation in Construction, Vol. 61, pp. 1-15.

Neill, U. S. (2008) Publish or Perish, but at What Cost?. Journal of Clinical Investigation, Vol. 118, No., 7, pp 2368-2368.

Office for National Statistics (2016) Annual Survey of Hours and Earnings (ASHE), Gross Annual Earnings for the 90 to 99 Percentiles of Employee Jobs in the UK and Regions for 
2004, 2010 and 2014, Office for National Statistics, London. Accessed via: http://www.ons.gov.uk/ (January 2016).

Parayil, G. (2005) The Digital Divide and Increasing Returns: Contradictions of Information Capitalism, The Information Society: An International Journal, Vol. 21, No. 1, pp 41-51. Pizarro, D.V., Price, D.L. and Beliveau, Y.J. (1997) Auditory Collision Warning Signals for Crane Operation, Automation ion Construction, Vol. 5, No. 6, pp 445-457.

Riaz, Z., Edwards, D.J. and Thorpe, A. (2006) SightSafety: A Hybrid Information and Communication Technology System for Reducing Vehicle/Pedestrian Collisions. Automation in Construction. Vol 15, No. 6, pp. 719 - 728.

Roberts, G. W., Dodson, A.H. and Ashkenazi, V. (1999) Global Positioning System Aided Autonomous Construction Plant Control and Guidance, Automation in Construction, Vol. 8, No. 5, pp. 1999 589-595.

Ross, A. (2016) Industries of the Future, Simon and Schuster: New York.

Teizer, J. Allead, B.S., Fullerton, C.E. and Hinze, J. (2010) Autonomous Pro-active RealTime Construction Worker and Equipment Operator Proximity Safety Alert System, Automation in Construction, Vol. 19, No. 5, pp. 630-640.

Turner, I.Y. and Huff, E.M. (2003) Analysis of Triaxial Vibration Data for Health Monitoring of Helicopter Gearboxes, Journal of Vibration Acoustics, Vol. 125, No. 1, pp $120-128$.

Tran, V.T and Yanga, B-S. (2012) An Intelligent Condition-based Maintenance Platform for Rotating Machinery, Expert Systems with Applications, Vol., 39, No. 3, pp. 2977-2988. Trivedi, M.M., Gandhi, T. and McCall, J. (2003) Looking-In and Looking-Out of a Vehicle: Computer-Vision-Based Enhanced Vehicle Safety, IEEE Transactions on Intelligent Transportation Systems, Vol. 8, No. 1, pp 108-120. 
Volvo (2016) EcoOperator, Volvo Construction Equipment: Duxford, UK. Accessed via: http://www.volvoce.com/dealers/en-gb/vcegb/products/plant-machine-excavatoroperator/Pages/plant-operator-training-fuel-economy.aspx (January, 2016)

Vulcan On-board Scales (2016) On-board Weighing System for the Trucking Industry : Washington, USA. Accessed via: http://www.vulcanscales.com/ (January, 2016).

Wang, D., Zheng, L. Yu, H., Zhou, W. and Shao, L. (2016) Robotic Excavator Motion Control Using a Nonlinear Proportional-Integrated Controller and Cross-Coupled Precompensation, Automation in Cnstruction, Vol. 64, pp. 1-6 